\title{
Spontaneous object recognition memory in aged rats: Complexity versus similarity
}

\author{
Fernando Gámiz ${ }^{1}$ and Milagros Gallo \\ Department of Psychobiology, Institute of Neurosciences, Center for Biomedical Research (CIBM), University of Granada, Granada \\ 18071, Spain
}

\begin{abstract}
Previous work on the effect of aging on spontaneous object recognition (SOR) memory tasks in rats has yielded controversial results. Although the results at long-retention intervals are consistent, conflicting results have been reported at shorter delays. We have assessed the potential relevance of the type of object used in the performance of aged rats in SOR tasks. Using standard objects, 24-mo-old rats did not exhibit retention impairment at a 1-h delay. At this retention interval no differences between young and old rats were found in a high-similarity SOR task, but aged rats exhibited deficits when clearly different complex forms were applied.
\end{abstract}

The spontaneous object recognition (SOR) task (Ennaceur and Delacour 1988), based on the innate tendency to explore novel objects more than familiar, has been thoroughly used to explore memory abilities at advanced ages in rodents. However, the results seem to depend on the retention interval applied. There is agreement on the age-related retention deficits with delays $>24 \mathrm{~h}$ (Bartolini et al. 1996; de Lima et al. 2005; Pieta Dias et al. 2007; Burke et al. 2010; Leite et al. 2011), but not at short retention intervals. Although some investigators found no age-related impairment in SOR memory testing at 1-min (Lukaszewska and Radulska 1994), 2-min (Burke et al. 2010), 3-min (Bergado et al. 2011), 5-min (Cavoy and Delacour 1993), and 1.5-h delays (de Lima et al. 2005; Pieta Dias et al. 2007; Leite et al. 2011), there are studies reporting deficits in aged rats at $2 \mathrm{~h}$ (Burke et al. 2010), $1 \mathrm{~h}$ (Scali et al. 1994, 1997; Vannucchi et al. 1997; Pitsikas et al. 2005; Da Silva Costa-Aze et al. 2011) and even at 60- or 30-sec retention periods (Willig et al. 1987; Bartolini et al. 1996).

Two variables could be relevant to explain these controversial findings. First, there is a great variety of objects used and they are not always well defined. They could be classified as standard objects, such as elemental everyday and junk objects (Aggleton et al. 1989; Lukaszewska and Radulska 1994; Liu et al. 2004; Hauser et al. 2009; Da Silva Costa-Aze et al. 2011), solid geometric forms including cubes, pyramids, and cylinders (Willig et al. 1987; Scali et al. 1994; Bartolini et al. 1996; Vannucchi et al. 1997; Pitsikas et al. 2005), and complex objects built of Lego blocks (de Lima et al. 2005; Pieta Dias et al. 2007; de Lima et al. 2008; Leite et al. 2011). Thus, it is difficult to evaluate the degree of dissimilarity and the difficulty level of the discrimination. This can be critical because ambiguity and complexity features have been proposed as essential variables determining SOR deficits in aged rats (Burke et al. 2010, 2011) and in adult PER lesioned rats (Buckley and Gaffan 1998; Eacott et al. 2001; Norman and Eacott 2004; Bartko et al. 2007a,b). In fact, the role of ambiguity in SOR performance has often been evaluated in configural tasks using complex objects (Bartko et al. 2007a, 2010). Also, the estimation of different memory indexes often renders comparisons difficult. Several ratios comparing novel versus familiar or total exploration times have been used either in addition to or instead of raw data (Bartolini et al. 1996; Vannucchi et al. 1997; Pitsikas et al.

\section{'Corresponding author}

E-mail fernandogamiz@ugr.es

Article is online at http://www.learnmem.org/cgi/doi/10.1101//m.027003.112.
2005; Pieta Dias et al. 2007; de Lima et al. 2008; Burke et al. 2010; Leite et al. 2011).

A series of experiments was aimed at assessing SOR memory in naïve aged rats at different retention intervals (Exp. 1) and with different types of objects: standard (Exp. 1), high-similarity/lowcomplexity solid forms (Exp. 2), and high-complexity/lowsimilarity Lego forms (Exp. 3). Additionally, special attention was paid to match the object exploration time (ET) during the familiarization phase of young and aged groups. Also the results obtained by estimating various memory indexes were compared.

A total number of 54 young (6- to 7-mo-old) and 52 aged (24-mo-old) male Wistar rats was used. In the first experiment they were assigned to each of four groups according to the retention interval applied: young $10 \mathrm{sec}(n=8), 60 \mathrm{sec}(n=10), 1 \mathrm{~h}$ $(n=8), 24 \mathrm{~h}(n=10)$, and aged $10 \mathrm{sec}(n=7), 60 \mathrm{sec}(n=7), 1 \mathrm{~h}$ $(n=10), 24 \mathrm{~h}(n=10)$. In Experiments 2 and 3 young and aged rats ( $n=9$ per group) received training in the water maze task (Morris 1984) 1 wk before applying the SOR task. This visually cued version allowed us to discard those visually impaired subjects that are not included in the total number mentioned above (data not shown).

All of the animals were housed individually and maintained on a 12-hr light-dark cycle. Food and water were available ad libitum during the whole behavioral procedure. Previously, only the old rats were subjected to caloric restriction from the age of $20 \mathrm{mo}$ to the beginning. The procedures were approved by the University of Granada Ethics Committee for Animal Research and were in accordance with the European Communities Council Directive 86/ 609/EEC.

The behavioral procedure took place in a black open plastic chamber $(40 \times 40 \times 40 \mathrm{~cm})$. It required three phases: (1) habituation during $5 \mathrm{~d}$ to the chamber after previous handling ( $2 \mathrm{~min}$ ) and room acclimatization (30 $\mathrm{min})$; (2) acquisition/familiarization ( $24 \mathrm{~h}$ later) in which the rat was allowed to explore the chamber containing two identical objects; each rat was allowed to explore until it accumulated $30 \mathrm{sec}$ of contact with the objects (nose within $2 \mathrm{~cm}$ of objects and vibrissae moving) or for a maximum of 5 min (Exp. 1) or 10 min (Exps. 2 and 3); and (3) retention test after a variable interval depending on the experiment. It consisted of a similar procedure to the acquisition, but while one of the objects was identical to that presented in the acquisition, the other one was novel. Both the object and the position were counterbalanced. Velcro was attached to each object to be secured to the floor. The retention test lasted either for the time required 
to accumulate $30 \mathrm{sec}$ of object ET (Exp. 1) or for a total time of 5 min (Exps. 2 and 3). The time that the rat spent exploring the objects was recorded with a video camera. Overhead lighting illuminated the testing area reducing room context information.

Subsequently, the following indexes were estimated. Discrimination ratio (DR) was the exploration difference between the novel and familiar object divided by the total ET (DR $=N-F /$ $\mathrm{N}+\mathrm{F}$ ) (Ennaceur and Delacour 1988). Recognition index (RI) consisted of dividing novel object exploration by the total ET (N/N + F) (Costa et al. 2008; Leite et al. 2011). Finally, a novel-familiar index (NFI) (Ennaceur and Delacour 1988) was estimated by subtracting the ET of the novel minus that of the familiar object (N-F).

There were three main variations in the behavioral procedure applied in each experiment. First, the ET during the acquisition phase lasted 5 min in Experiment 1, while in Experiments 2 and 3 the object ET of each young rat was matched to that of one old rat, to a maximum of $10 \mathrm{~min}$. In addition, the retention test lasted for 5 min in Experiments 2 and 3, while in Experiment 1 the rats were allowed to explore the time required to accumulate $30 \mathrm{sec}$ of total object ET. Second, the retention intervals applied in the first experiment lasted $10 \mathrm{sec}, 60 \mathrm{sec}, 1 \mathrm{~h}$, or $24 \mathrm{~h}$ depending on the group assignment. However, a 1-h retention interval was used in Experiments 2 and 3. This was the longest retention interval tested that was not affected by aging in the first experiment. Finally, the critical difference among the experiments lies in the stimuli used. Figure 1a shows the stimuli used in Experiment 1 that were two identical copies of a plastic apple and a porcelain jar ( $\sim 12 \mathrm{~cm}$ high and $8 \mathrm{~cm}$ wide). In the second experiment (simple/similar objects) a pair of elemental geometrics was chosen (Fig. 1b). They were a dark blue (Pantone 280) regular pentagonbased pyramid versus a dark green (Pantone 349 ) regular hexagonbased pyramid ( $12 \mathrm{~cm}$ high and $8 \mathrm{~cm}$ wide). Therefore, the forms to be discriminated were similar, differing only in the number of planes. In the third experiment (complex/different objects) a pair of complex tridimensional forms were built of Lego bricks (Lego Basic Bricks-Standart ref: 5529), each figure containing 30 pieces. The global shape was clearly intended to differ (Fig. 1c). Thus, object 1 measured $7 \mathrm{~cm}$ high and $12 \mathrm{~cm}$ wide, while object 2 measured $12 \mathrm{~cm}$ high and $15 \mathrm{~cm}$ wide.

In Experiment 1 there were no differences in ET among the groups during the acquisition phase $\left(F_{(1,68)}=2.44 ; P>0.12\right)$. ANOVA analyses $4 \times 2 \times 2$ (retention interval $\times$ age $\times$ novelty) yielded a significant effect of novelty $\left(F_{(1,62)}=42.93 ; P<0.01\right)$, indicating longer exploration of the novel object during the retention test. No other effect was significant. Independent $2 \times 2$ ANOVA analyses (Fig. 2a) at $10 \mathrm{sec}, 60 \mathrm{sec}$, and $1 \mathrm{~h}$ intervals yielded similar results. However, the analysis at the $24 \mathrm{~h}$ retention interval showed a significant effect of the main factor novelty $\left(F_{(1,18)}=\right.$ $8.36 ; P<0.01)$ and the interaction age $\times$ novelty $\left(F_{(1,18)}=11.13\right.$; $P<0.01)$. The young group spent longer time exploring the novel object than the familiar $\left(F_{(1,9)}=16.9 ; P<0.01\right)$, but there were no differences in the ET of the novel versus the familiar object in the aged group $\left(F_{(1,9)}=0.11 ; P>0.74\right)$. Moreover, the aged group exhibited lower ET of the novel object $\left(F_{(1,18)}=11.13 ; P<0.01\right)$ and longer ET of the familiar object $\left(F_{(1,18)}=11.13 ; P<0.01\right)$ than the young group.

Consistently, the aged and young groups differed at the 24-h retention interval when applying the most commonly SOR indexes: DR $\left(F_{(1,18)}=11.21 ; P<0.01\right)$ (Fig. $\left.2 b\right)$, RI $\left(F_{(1,18)}=10.95 ; P<\right.$ $0.01)$ (Fig. 2 c) and NFI $\left(F_{(1,18)}=11.13\right.$; and $\left.P<0.01\right)$ (Fig. 2 d).

With respect to Experiments 2 (simple/similar) and 3 (complex/different), due to yoking there were no age differences in the total ET of the objects during acquisition. Regarding the testing session performed at the 1 -h retention interval a $2 \times 2 \times 2$ (age $\times$ object $\times$ novelty) ANOVA analysis, including data from both experiments, showed a significant interaction of the three factors
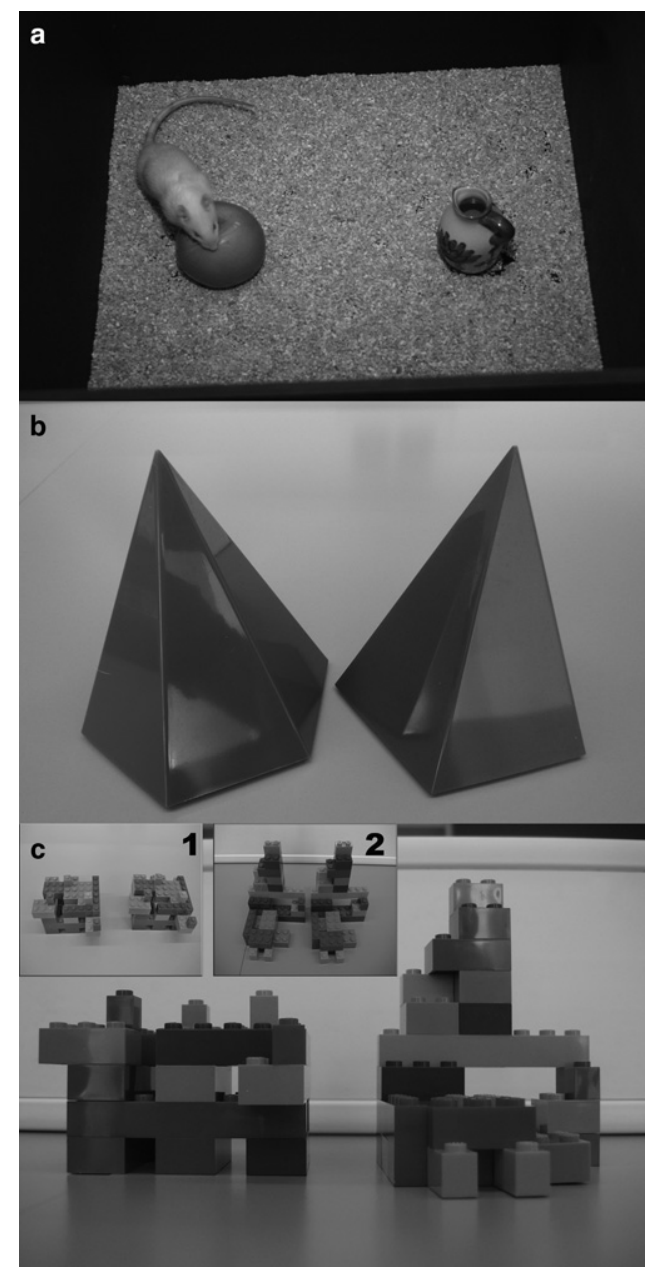

Figure 1. Photographs of the objects' pairs used in the SOR experiments. (a) Standard objects consisting of a plastic apple versus a porcelain jar (Exp. 1). (b) Simple/ambiguous objects consisting of a regular pentagon-based pyramid versus a regular hexagon-based pyramid. (c) Complex/unambiguous objects built with Duplo Lego bricks of five different colors. Insets ( 1 and 2 ) show a perspective from a different angle of the corresponding sample pairs during familiarization.

$\left(F_{(1,32)}=5.34 ; P<0.05\right)$. A $2 \times 2$ (age $\times$ novelty) ANOVA analysis of the object ETs in Experiment 2 revealed significant main effects of novelty $\left(F_{(1,16)}=26.53 ; P<0.01\right)$ and age $\left(F_{(1,16)}=13.65 ; P<\right.$ 0.01 ), but not the interaction. Both young and aged groups explored the novel object longer than the familiar (Fig 3a), thus indicating recognition when using elemental solid forms even if they were similar. The analyses of the SOR indexes did not evidence any significant difference between the groups (Fig. 3b-d).

However, a similar analysis of Experiment 3 results revealed the main significant effects of age $\left(F_{(1,16)}=8.21 ; P<0.01\right)$ and the interaction age $\times$ novelty $\left(F_{(1,16)}=13.07 ; P<0.01\right)$ (Fig. 3e). The analysis of the interaction showed that the young group explored the novel longer than the familiar object $\left(F_{(1,8)}=16.86\right.$; $P<0.01$ ), while the aged group did not show significant differences $\left(F_{(1,8)}=1.11 ; P>0.32\right)$. Also, the novel object ET was higher in the young than in the aged group $\left(F_{(1,16)}=16.89 ; P<0.01\right)$, but there were no differences between the groups in the time spent exploring the familiar object. Consistently, the analysis based on NFI ratios yielded a significant age $\times$ object interaction $\left(F_{(1,32)}=5.34\right.$; $P<0.05$ ), thus confirming the age effect in the complex/different 

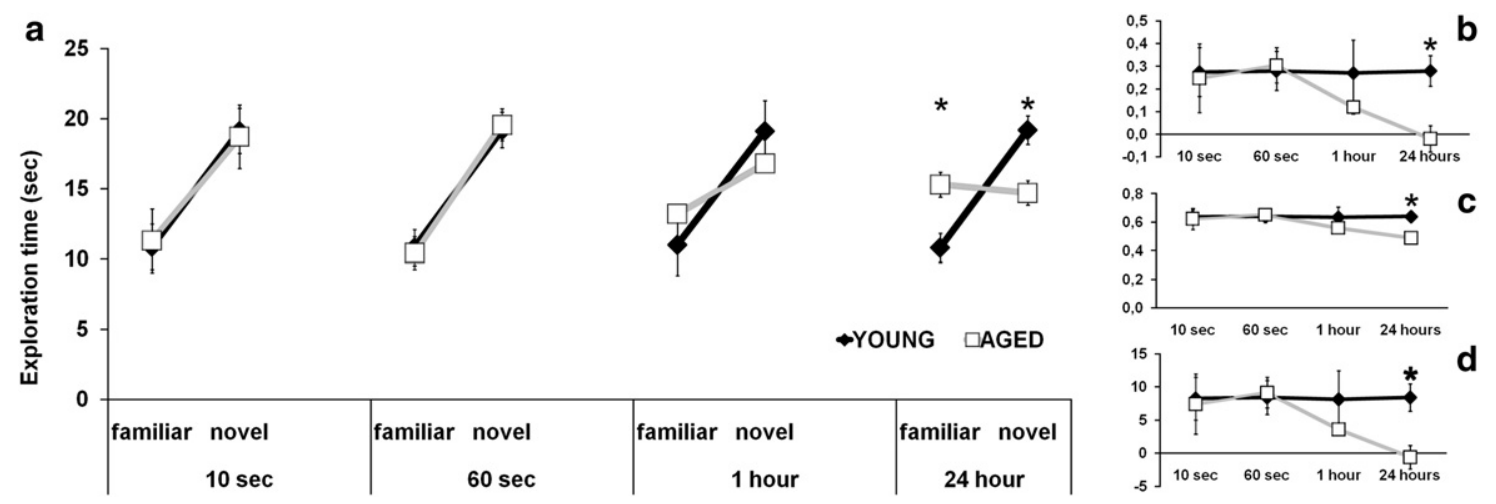

Figure 2. Spontaneous object recognition (SOR) task performance at different retention intervals during the testing phase using standard objects. (a) Mean ( \pm SEM) ET of young (filled squares) and aged (open squares) groups. (b) Mean ( \pm SEM) discrimination ratio scores $(D R=N-F / N+F)$ of the adult and aged group. (c) Mean ( \pm SEM) recognition index scores $(\mathrm{RI}=\mathrm{N} / \mathrm{N}+\mathrm{F}$ ) of the young and aged group. (d) Mean ( \pm SEM) scores using the novelfamiliar index $(\mathrm{NFI}=\mathrm{N}-\mathrm{F})$ of the young and aged group. (F) Familiar object; $(\mathrm{N})$ novel object; $\left({ }^{*}\right) P<0.05$.

SOR task, but not in the simple/similar. However, no other index detected this interaction, since only the effect of age and obviating the relevance of the object type were significant.

The main finding of Experiment 1 was to identify retention intervals at which aged rats would perform similarly to young rats. Although the performance of aged and young rats differed at the 24-h retention interval, the interaction was not significant. These results are consistent with most of the previous reports (de Lima et al. 2005; Pieta Dias et al. 2007; Burke et al. 2010; Leite et al. 2011), in spite of the fact that some aging studies have found differences between aged and young rats in this range of retention intervals (Scali et al. 1994; Bartolini et al. 1996; Vannucchi et al. 1997; Pitsikas et al. 2005).

Among the potential explanations, a reduced object ET by the aged groups during acquisition does not seem to be critical in the present experiment given the similar performance of aged and young groups. However, some studies had reported a reduced exploration in aged rats (Liu et al. 2004; Bergado et al. 2011), which might lead to confusing results when compared with young groups. Therefore, in Experiments 2 and 3, yoked young groups were used to ensure similar ETs.

The most feasible explanation for the controversial effects of aging in SOR memory tasks might be the objects used. In Experiment 1 we used standard objects that differed in material, shape, size, and color. Aging studies using SOR tasks have applied a great variety of standard objects (Aggleton et al. 1989; Lukaszewska and Radulska 1994; Liu et al. 2004; Hauser et al. 2009), since the use of clearly different elemental stimuli is common (Cavoy and Delacour 1993; Burke et al. 2010; Bergado et al. 2011). However, they are often poorly described and not easily found all over the world, rendering it difficult to replicate the experiments. Since subtle modifications of the object's features in SOR tasks has proven to be relevant for involving different brain areas such as PER cortex (Ennaceur and Aggleton 1997; Eacott et al. 2001; Murray and Richmond 2001; Norman and Eacott 2004; Winters et al. 2004; Winters and Bussey 2005b; Bartko et al. 2007a, 2010; Cowell et al. 2010), a precise description is included. In this respect, it has been suggested that SOR memory impairments in aged rats could be related to PER dysfunction (Burke et al. 2010, 2011). There is some controversy about the brain areas involved in stimulus recognition both in rodents and primates (Mishkin 1978; Zola-Morgan et al. 1982; Saunders et al. 1984; Clark et al. 2000; Zola et al. 2000; Broadbent et al. 2004). A growing number of studies point to the perirhinal (PER) cortex as the key structure (Ennaceur and Aggleton 1997; Wiig and Burwell
1998; Baxter and Murray 2001; Ranganath et al. 2004; Winters et al. 2004; Winters and Bussey 2005a,b; Burke et al. 2010). However, due to the potential age-related widespread brain dysfunction other explanations cannot be excluded.

The findings of Experiments 2 and 3 confirm the relevance of dissociating the effect of object complexity, often related with ambiguity, from that of perceptual similarity on the performance of aged rats. Old rats did not exhibit difficulties in recognizing simple geometric forms (pyramids) $1 \mathrm{~h}$ after the acquisition, even if
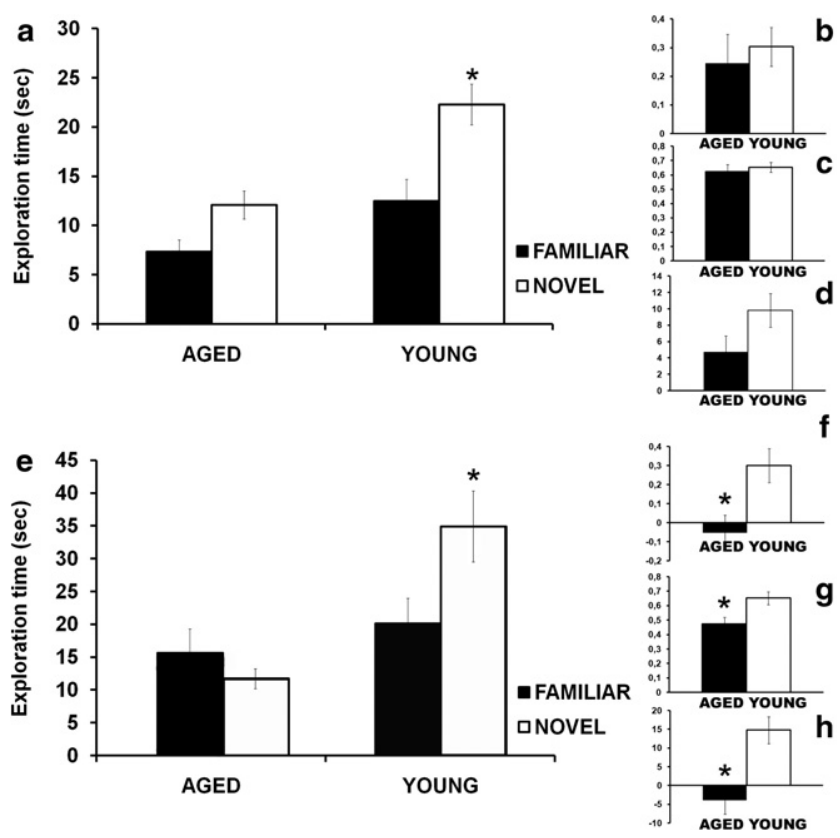

Figure 3. Young versus aged groups' performance in the SOR task using simple/ambiguous and complex/unambiguous objects at the 1-h retention interval. (a) Mean ( \pm SEM) ET of the familiar (black) versus the novel (white) object during the testing phase with simple/ambiguous objects (Exp. 2). (b) Mean ( \pm SEM) DR scores in Experiment 2. (c) Mean ( \pm SEM) RI scores in Experiment 2. (d) Mean ( \pm SEM) NFI scores in Experiment 2. (e) Mean ( \pm SEM) ET of the familiar (black) and the novel (white) object during the testing phase with complex/unambiguous objects (Exp. 3). ( $f$ ) Mean ( \pm SEM) DR scores in Experiment 3. $(g)$ Mean ( \pm SEM) RI scores in Experiment 3. (h) Mean ( \pm SEM) NFI scores in Experiment 3. $\left(^{*}\right) P<0.05$. 
the discrimination was difficult and the objects differed only in one plane. However, at the same retention interval they showed lower performance than young rats with complex but clearly different objects made of Lego bricks. Therefore, aging seems to selectively affect the processing of the configural aspects of complex objects. These findings might be consistent with previous results emphasizing the relevance of ambiguity to explain SOR deficits using complex objects. It should be noted that feature ambiguity is maximized in discriminations involving complex objects (Aggleton et al. 2010). However, it also should be present in Experiment 2 since it cannot be solved by a particular feature (one plane), requiring the unique combination of planes in each pyramid. Therefore, a definition of ambiguity should take into account complexity and difficulty of the discrimination.

Although it has been reported that caloric restriction can reduce negative effects of aging in exploratory behavior, SOR tasks do not seem to be sensitive or are even negatively affected by food restriction in aged rats (Carter et al. 2009). Moreover, the fact that aged rats selectively exhibited a good performance using simple/similar but not complex/different objects does not support a relevant role of the caloric restriction treatment applied before the behavioral procedure.

Finally, the results support the need for reporting information about raw data to permit comparisons among studies, and also detect mild age-related deficits. In the present experiments only NFI was as sensitive as raw data.

In summary, it is our point of view that a careful control of procedural variables will help to draw conclusions on the effect of normal aging in object recognition memory. This study has explored the relevance of the retention interval to dissociate impaired and unimpaired object recognition abilities at a 1-h retention interval, depending on the complexity and similarity of the objects used. Therefore, paying greater attention to the nature of the objects to be discriminated will be of great help not only for increasing reproducibility and allowing comparisons among experiments, but also to identify the selective decay of perceptual-mnemonic processes and the brain structures involved.

\section{Acknowledgments}

Supported by research projects HUM 02763 (Junta de Andalucía, Spain), PSIC2008-03933, (MICINN, Spain), PSIC2011-23702, and FPU fellowship to F.G. (MICINN, Spain).

\section{References}

Aggleton JP, Blindt HS, Candy JM. 1989. Working memory in aged rats. Behav Neurosci 103: 975-983.

Aggleton JP, Albasser MM, Aggleton DJ, Poirier GL, Pearce JM. 2010. Lesions of the rat perirhinal cortex spare the acquisition of a complex configural visual discrimination yet impair object recognition. Behav Neurosci 124: 55-68.

Bartko SJ, Winters BD, Cowell RA, Saksida LM, Bussey TJ. 2007a. Perceptual functions of perirhinal cortex in rats: Zero-delay object recognition and simultaneous oddity discriminations. J Neurosci 27: 2548-2559.

Bartko SJ, Winters BD, Cowell RA, Saksida LM, Bussey TJ. 2007b. Perirhinal cortex resolves feature ambiguity in configural object recognition and perceptual oddity tasks. Learn Mem 14: 821-832.

Bartko SJ, Cowell RA, Winters BD, Bussey TJ, Saksida LM. 2010. Heightened susceptibility to interference in an animal model of amnesia: Impairment in encoding, storage, retrieval-or all three? Neuropsychologia 48: 2987-2997.

Bartolini L, Casamenti F, Pepeu G. 1996. Aniracetam restores object recognition impaired by age, scopolamine, and nucleus basalis lesions. Pharmacol Biochem Behav 53: 277-283.

Baxter MG, Murray EA. 2001. Impairments in visual discrimination learning and recognition memory produced by neurotoxic lesions of rhinal cortex in rhesus monkeys. Eur J Neurosci 13: 1228-1238.
Bergado JA, Almaguer W, Rojas Y, Capdevila V, Frey JU. 2011. Spatial and emotional memory in aged rats: A behavioral-statistical analysis. Neuroscience 172: 256-269.

Broadbent NJ, Squire LR, Clark RE. 2004. Spatial memory, recognition memory, and the hippocampus. Proc Natl Acad Sci 101: 14515-14520.

Buckley MJ, Gaffan D. 1998. Perirhinal cortex ablation impairs visual object identification. J Neurosci 18: 2268-2275.

Burke SN, Wallace JL, Nematollahi S, Uprety AR, Barnes CA. 2010. Pattern separation deficits may contribute to age-associated recognition impairments. Behav Neurosci 124: 559-573.

Burke SN, Wallace JL, Hartzell AL, Nematollahi S, Plange K, Barnes CA. 2011. Age-associated deficits in pattern separation functions of the perirhinal cortex: A cross-species consensus. Behav Neurosci 125: $836-847$.

Carter CS, Leeuwenburgh C, Daniels M, Foster TC. 2009. Influence of calorie restriction on measures of age-related cognitive decline: Role of increased physical activity. J Gerontol A Biol Sci Med Sci 64: $850-859$.

Cavoy A, Delacour J. 1993. Spatial but not object recognition is impaired by aging in rats. Physiol Behav 53: 527-530.

Clark RE, Zola SM, Squire LR. 2000. Impaired recognition memory in rats after damage to the hippocampus. J Neurosci 20: 8853-8860.

Costa MS, Botton PH, Mioranzza S, Ardais AP, Moreira JD, Souza DO, Porciuncula LO. 2008. Caffeine improves adult mice performance in the object recognition task and increases BDNF and TrkB independent on phospho-CREB immunocontent in the hippocampus. Neurochem Int 53: $89-94$.

Cowell RA, Bussey TJ, Saksida LM. 2010. Components of recognition memory: Dissociable cognitive processes or just differences in representational complexity? Hippocampus 20: 1245-1262.

Da Silva Costa-Aze V, Dauphin F, Boulouard M. 2011. Serotonin 5-HT6 receptor blockade reverses the age-related deficits of recognition memory and working memory in mice. Behav Brain Res 222: 134-140.

de Lima MN, Laranja DC, Caldana F, Bromberg E, Roesler R, Schroder N. 2005. Reversal of age-related deficits in object recognition memory in rats with l-deprenyl. Exp Gerontol 40: 506-511.

de Lima MN, Dias CP, Torres JP, Dornelles A, Garcia VA, Scalco FS, Guimaraes MR, Petry RC, Bromberg E, Constantino L, et al. 2008. Reversion of age-related recognition memory impairment by iron chelation in rats. Neurobiol Aging 29: 1052-1059.

Eacott MJ, Machin PE, Gaffan EA. 2001. Elemental and configural visual discrimination learning following lesions to perirhinal cortex in the rat. Behav Brain Res 124: 55-70.

Ennaceur A, Aggleton JP. 1997. The effects of neurotoxic lesions of the perirhinal cortex combined to fornix transection on object recognition memory in the rat. Behav Brain Res 88: 181-193.

Ennaceur A, Delacour J. 1988. A new one-trial test for neurobiological studies of memory in rats. 1: Behavioral data. Behav Brain Res 31: 47-59.

Hauser E, Tolentino JC, Pirogovsky E, Weston E, Gilbert PE. 2009. The effects of aging on memory for sequentially presented objects in rats. Behav Neurosci 123: 1339-1345.

Leite MR, Wilhelm EA, Jesse CR, Brandao R, Nogueira CW. 2011. Protective effect of caffeine and a selective A2A receptor antagonist on impairment of memory and oxidative stress of aged rats. Exp Gerontol 46: 309-315.

Liu P, Smith PF, Appleton I, Darlington CL, Bilkey DK. 2004. Potential involvement of NOS and arginase in age-related behavioural impairments. Exp Gerontol 39: 1207-1222.

Lukaszewska I, Radulska A. 1994. Object recognition is not impaired in old rats. Acta Neurobiol Exp (Wars) 54: 143-150.

Mishkin M. 1978. Memory in monkeys severely impaired by combined but not by separate removal of amygdala and hippocampus. Nature 273: 297-298.

Morris R. 1984. Developments of a water-maze procedure for studying spatial learning in the rat. J Neurosci Methods 11: 47-60.

Murray EA, Richmond BJ. 2001. Role of perirhinal cortex in object perception, memory, and associations. Curr Opin Neurobiol 11: $188-193$.

Norman G, Eacott MJ. 2004. Impaired object recognition with increasing levels of feature ambiguity in rats with perirhinal cortex lesions. Behav Brain Res 148: 79-91.

Pieta Dias C, Martins de Lima MN, Presti-Torres J, Dornelles A, Garcia VA, Siciliani Scalco F, Rewsaat Guimaraes M, Constantino L, Budni P, Dal-Pizzol F, et al. 2007. Memantine reduces oxidative damage and enhances long-term recognition memory in aged rats. Neuroscience 146: $1719-1725$

Pitsikas N, Rigamonti AE, Cella SG, Sakellaridis N, Muller EE. 2005. The nitric oxide donor molsidomine antagonizes age-related memory deficits in the rat. Neurobiol Aging 26: 259-264.

Ranganath C, Yonelinas AP, Cohen MX, Dy CJ, Tom SM, D’Esposito M. 2004. Dissociable correlates of recollection and familiarity within the medial temporal lobes. Neuropsychologia 42: 2-13. 
Saunders RC, Murray EA, Mishkin M. 1984. Further evidence that amygdala and hippocampus contribute equally to recognition memory. Neuropsychologia 22: 785-796.

Scali C, Casamenti F, Pazzagli M, Bartolini L, Pepeu G. 1994. Nerve growth factor increases extracellular acetylcholine levels in the parietal cortex and hippocampus of aged rats and restores object recognition. Neurosci Lett 170: 117-120.

Scali C, Giovannini MG, Bartolini L, Prosperi C, Hinz V, Schmidt B, Pepeu G. 1997. Effect of metrifonate on extracellular brain acetylcholine and object recognition in aged rats. Eur J Pharmacol 325: 173-180.

Vannucchi MG, Scali C, Kopf SR, Pepeu G, Casamenti F. 1997. Selective muscarinic antagonists differentially affect in vivo acetylcholine release and memory performances of young and aged rats. Neuroscience 79: $837-846$.

Wiig KA, Burwell RD. 1998. Memory impairment on a delayed nonmatching-to-position task after lesions of the perirhinal cortex in the rat. Behav Neurosci 112: 827-838.

Willig F, Palacios A, Monmaur P, M'Harzi M, Laurent J, Delacour J. 1987. Short-term memory, exploration and locomotor activity in aged rats. Neurobiol Aging 8: 393-402.
Winters BD, Bussey TJ. 2005a. Removal of cholinergic input to perirhinal cortex disrupts object recognition but not spatial working memory in the rat. Eur J Neurosci 21: 2263-2270.

Winters BD, Bussey TJ. 2005b. Transient inactivation of perirhinal cortex disrupts encoding, retrieval, and consolidation of object recognition memory. J Neurosci 25: 52-61.

Winters BD, Forwood SE, Cowell RA, Saksida LM, Bussey TJ. 2004 Double dissociation between the effects of peri-postrhinal cortex and hippocampal lesions on tests of object recognition and spatial memory: Heterogeneity of function within the temporal lobe. J Neurosci 24: 5901-5908.

Zola-Morgan S, Squire LR, Mishkin M. 1982. The neuroanatomy of amnesia: Amygdala-hippocampus versus temporal stem. Science 218: $1337-1339$

Zola SM, Squire LR, Teng E, Stefanacci L, Buffalo EA, Clark RE. 2000. Impaired recognition memory in monkeys after damage limited to the hippocampal region. J Neurosci 20: 451-463.

Received May 10, 2012; accepted in revised form June 7, 2012. 


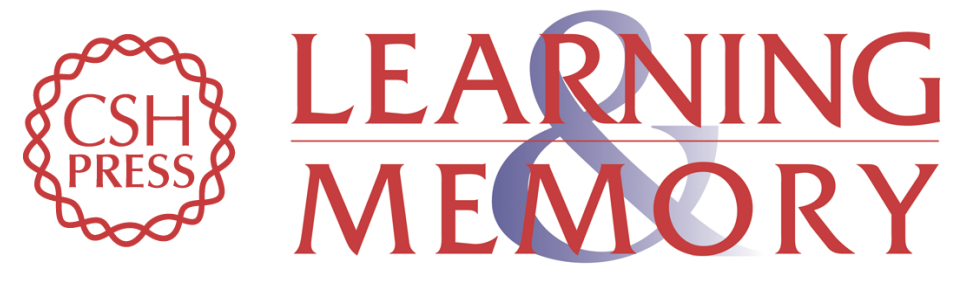

\section{Spontaneous object recognition memory in aged rats: Complexity versus similarity}

Fernando Gámiz and Milagros Gallo

Learn. Mem. 2012, 19:

Access the most recent version at doi:10.1101//m.027003.112

References This article cites 45 articles, 9 of which can be accessed free at:

http://learnmem.cshlp.org/content/19/10/444.full.html\#ref-list-1

License

Email Alerting Receive free email alerts when new articles cite this article - sign up in the box at the Service top right corner of the article or click here. 